\section{"Tu turno al barrio": propuesta de referencia- contrarreferencia entre los niveles de atención de la salud}

Señor editor: Mediante la presente intentamos compartir una experiencia que ha resultado exitosa en nuestro país, Argentina, en el terreno de la comunicación entre el primer y segundo nivel de atención de la salud subsector estatal.

En nuestro país, como en la mayor parte de los países de Latinoamérica, el primer nivel de atención se encuentra desarticulado de los de mayor complejidad, ${ }^{1}$ a pesar que la Organización Mundial de la Salud (OMS) promueve un sistema en el que las personas no accedan a servicios aislados de salud sino a una red de los mismos. $^{2}$

La presente experiencia se desarrolla en la provincia de Buenos Aires, donde gran parte de la población evita consultar los Centros de Atención Primaria de la Salud (CAPS) cercanos de su domicilio y acude directamente a hospitales de mayor comple- jidad. Esto motiva un recorrido innecesario de grandes distancias, saturación de los servicios hospitalarios, demora en la consulta y deterioro en la calidad de atención.

Resulta necesario incorporar al paradigma de la atención primaria de la salud (APS) el concepto de redes integradas de salud de complejidad creciente.,4 Para ello es requisito indispensable disponer de sistemas de comunicación que hagan efectivo este trabajo en red, incorporando tecnologías que faciliten la gestión y mejoren la información. ${ }^{4,5}$

Por este motivo, diseñamos un sistema de optimización llamado "Tu turno al barrio" que incorpora tecnología de bajo costo al primer nivel como modo de solucionar el problema de la referencia y contrarreferencia (R/Crf), y a la vez reducir el gasto de bolsillo de los pacientes. Cabe aclarar que los centros de salud del municipio no cuentan con computadoras ni con un sistema organizado de R/Crf, situación que genera dificultades en la atención de los pacientes tal como objetivamos y presentamos en el cuadro I.

"Tu turno al barrio" consta de una terminal sumamente sencilla de correo electrónico que utiliza la red de teléfono, solicitándose desde cada uno de los nueve CAPS del Municipio de Berisso (de casi 100 mil habitantes) los turnos que los profesionales de la salud de dichos centros requieran para sus pacientes. Un sistema similar se encuentra en el hospital de segundo nivel de referencia, y es capaz de brindar fecha, hora y profesional que efectuará la consulta o práctica solicitada. La experiencia consiste pues en un estudio de intervención con evaluación previa y a 12 meses después de su comienzo. Inicialmente observamos las barreras de accesibilidad que debían sortear los pacientes para ser asistidos en el segundo nivel. Conseguir un turno hospitalario requería en promedio 7.4 horas/paciente y un recorrido de 8.82 kilómetros/paciente, con un costo de traslado promedio de 3.9 dólares por persona. La interconsulta o la práctica solicitada demoraban aproximadamente un mes.

La propuesta de modificación comenzó en mayo de 2006, y luego del año de funcionamiento se realizó una nueva 
Cuadro I

CuANTIFICACIÓN dE OBSTÁCULOS A LA ACCESIBILIDAD PARA LA OBTENCIÓN DE TURNO HOSPITALARIO

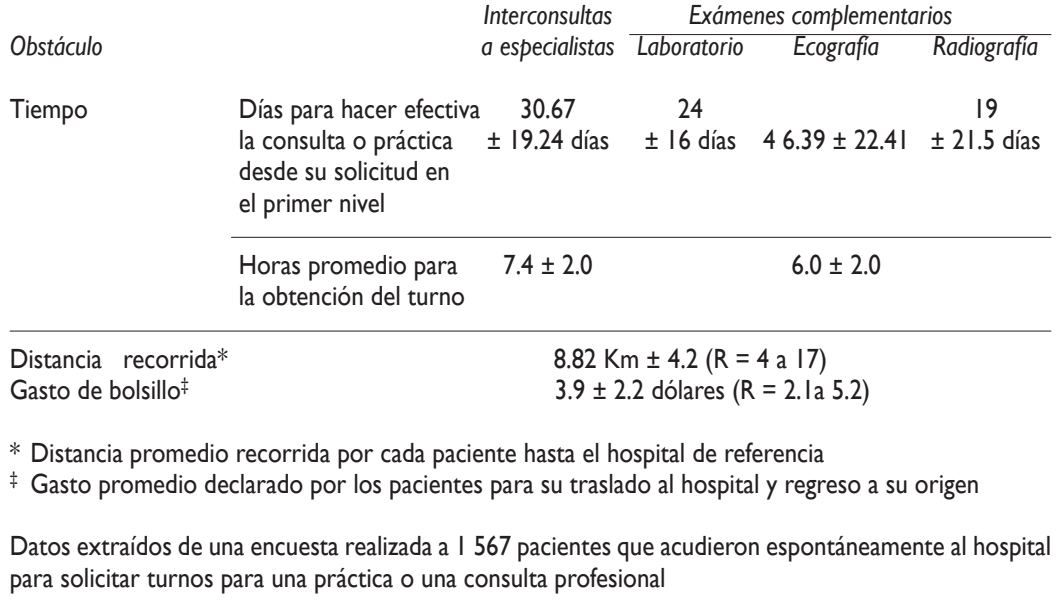

medición de las variables seleccionadas en la etapa previa a la implementación de la propuesta.

El sistema fue utilizado para la atención de 5035 pacientes, evitándose un total de 11077 traslados a partir de la implementación del sistema.

El cuadro II muestra la comparación de la demora en días para obtener un turno antes y después de la intervención, y el porcentaje de cumplimiento de las solicitudes de referencia por parte de los pacientes antes y después del programa.
Con el sistema también se evitaron en $100 \%$ las demoras para conseguir un turno y los costos de traslado. Se redujeron además las demoras en la realización de las interconsultas o las prácticas y el número total de consultas o estudios complementarios no realizados.

El costo operativo del programa durante los 12 meses de utilización fue de 46.08 dólares, lo que significa que se de este sistema, a un costo de 0.004 dólares por traslado. realizaron los 11077 traslados a través
Esto resulta en $99.89 \%$ de ahorro respecto del gasto directo de bolsillo que cada paciente destinaba a su traslado para la obtención de un turno ( 3.9 dólares).

Lo anterior significa un enorme ahorro no sólo para las instituciones sino también para el gasto de bolsillo de la población. Un aporte que dio valor agregado a la propuesta es el monitoreo, no sólo porque permite corregir diariamente las fallas del sistema, sino porque posee la externalidad sobre los agentes integrantes del sistema de salud respecto de su percepción de control.

Optimizar la comunicación entre los niveles de atención posee beneficios no sólo para el propio sistema de salud sino, principalmente, para los usuarios del mismo en quienes se puede medir el impacto positivo del cambio, en términos de tiempo, costos y calidad de la atención.

$D$ en M Gustavo Horacio Marin, M en SP, M en ES Universidad Nacional de la Plata,Argentina Ministerio de Salud de la provincia de Buenos Aires gmarin@netverk.com.ar

Dr. Martin Silberman, M en SP Universidad Nacional de la Plata,Argentina silbermanmartin@gmail.com Dra. Cecilia Homar, M en SP Universidad Nacional de la Plata,Argentina cecihom@hotmail.com

\section{Cuadro II}

\section{Comparación de los RESULtAdos ANTES Y DESPUÉS DE LA EXPERIENCIA}

\begin{tabular}{|c|c|c|c|c|c|c|}
\hline $\begin{array}{c}\text { Tiempo } \\
\text { de evaluación }\end{array} \quad \begin{array}{c}\text { Variable } \\
\text { analizada }\end{array}$ & $\begin{array}{c}\text { Demora } \\
\text { en realización } \\
\text { de interconsulta } \\
\text { (días) }\end{array}$ & $\begin{array}{l}\text { Demora } \\
\text { en realización } \\
\text { de radiografias } \\
\text { (días) }\end{array}$ & $\begin{array}{l}\text { Demora } \\
\text { en realización } \\
\text { de laboratorio } \\
\text { (días) }\end{array}$ & $\begin{array}{l}\text { Demora } \\
\text { en realización } \\
\text { de ecografia } \\
\text { (días) }\end{array}$ & $\begin{array}{c}\text { Porcentaje } \\
\text { de interconsultas } \\
\text { no realizadas }\end{array}$ & $\begin{array}{l}\text { Porcentaje } \\
\text { de estudios } \\
\text { complementarios } \\
\text { no realizados }\end{array}$ \\
\hline Antes de la implementación & $30,67 \pm 19.2$ & $19,78 \pm 21.5$ & $24,09 \pm 16$ & $46,4 \pm 22.4$ & 30.22 & 23,47 \\
\hline Después de la implementación & $18,35 \pm 11.2$ & $9,51 \pm 3.4$ & $11,83 \pm 5.3$ & $26,95 \pm 11.5$ & 18,14 & $|I, 2|$ \\
\hline \% de reducción & $40.17^{*}$ & $51.93 *$ & $50.90 *$ & $41.91 *$ & 39.12 & $52.24 *$ \\
\hline$*_{p}<0.05$ & & & & & & \\
\hline
\end{tabular}




\section{Referencias}

I. Organización Panamericana de la Salud, Organización Mundial de la Salud, $44^{\circ}$ Consejo Consultivo.Atención primaria de la salud en las Américas: las enseñanzas extraídas a lo largo de 25 años y los retos futuros. Septiembre de 2003.
Washington, DC: Organización Panamericana de la Salud, Organización Mundial de la Salud, 2003 2. Organización Mundial de la Salud. Informe de Salud en el Mundo, 2003. Ginebra: OMS, 2003 3. Ortún V. La articulación entre niveles asistenciales. En: Del Llano J, Ortún V, MartínMoreno JM, Millán J, Gené J. Barcelona: Masson, 1998: 349-357.
4. Castillo A, Vargas U. ¿Continuidad de la atención o falta de recursos en el primer nivel de atención en los servicios de salud de la CCSS? Rev cienc adm financ segur soc 2003; I I:.45-49. 5. Grupo para la Asistencia Médica Integrada y Continua de Cádiz (GAMIC). Evaluación de la consultoría entre internistas y médicos de familia a los 42 meses de su implantación. Investig Clin Farm 2005; 2(3): 127-137. 